\title{
Integrated implementation of evidence-based interventions to increase colorectal cancer screening through public health-primary care partnerships
}

\section{Cindy Soloe ( $\nabla$ csoloe@rti.org )}

RTI International https://orcid.org/0000-0001-7615-4952

\section{Laura Arena}

RTI International

\section{Dara Schlueter}

Division of Cancer Prevention and Control, Centers for Disease Control and Prevention

\section{Stephanie Melillo}

Division of Cancer Prevention and Control, Centers for Disease Control and Prevention

\section{Amy DeGroff}

Division of Cancer Prevention and Control, Centers for Disease Control and Prevention

\section{Florence Tangka}

Division of Cancer Prevention and Control, Centers for Disease Control and Prevention

\section{Sonja Hoover}

RTI International

\section{Sujha Subramanian}

RTI International

\section{Research}

Keywords: colorectal cancer screening, public health, partnership, evidence-based interventions

Posted Date: December 15th, 2020

DOl: https://doi.org/10.21203/rs.3.rs-127902/v1

License: (c) (i) This work is licensed under a Creative Commons Attribution 4.0 International License. Read Full License 


\section{Abstract \\ Background}

In 2015, the Centers for Disease Control and Prevention funded the Colorectal Cancer Control Program (CRCCP), which partners with health systems and primary care clinics to increase CRC screening uptake. We interviewed CRCCP stakeholders to explore factors that support an integrated implementation of evidence-based interventions and supporting activities to promote CRC screening with other screening and chronic disease management activities in primary care clinics.

\section{Methods}

Using the Consolidated Framework for Implementation Research, we conducted a literature review and identified constructs to guide data collection and analysis. We purposively selected four CRCCP awardees that demonstrated ongoing engagement with clinic partner sites, willingness to collaborate with CDC and other stakeholders, and availability of high-quality data. We gathered background information on the selected program sites and conducted primary data collection interviews with program staff and partners. We used NVivo QSR 11.0 to systematically pilot-code interview data, achieving a Kappa coefficient of 0.8 or higher, and then implemented a stepwise process to identify site-specific and cross-cutting emergent themes.

\section{Results}

Programs reported that they support clinic partners' integrated implementation by providing coordinated application processes and braided funding streams, and by funding partner organizations to provide technical assistance to support efficient implementation of evidence-based interventions and supporting activities into existing clinic workflows. These actions, in turn, support clinics in implementing evidencebased interventions and supporting activities that promote both CRC screening and other chronic disease screening and management.

\section{Discussion}

The selected CRCCP programs and their partners implement activities to support the integration of evidence-based interventions and supporting activities with other clinic efforts. These integrated efforts support increased efficiency of clinic workflow, improved coordination of patient care, increased uptake of screening and improved patient outcomes.

\section{Conclusions}


The findings provide insights into how public health programs can support primary care clinics in integrating interventions and activities into existing workflows to support efficient, coordinated delivery of quality patient-centered care.

\section{Contributions To The Literature}

- Describes how Colorectal Cancer Control Program public health and primary care partnerships support integrated implementation of evidence-based interventions and supporting activities to promote colorectal cancer screening and management of other chronic diseases.

- Provides insights into how public health programs and primary care clinics can collectively support integrated implementation of interventions into clinic workflows to support efficient, coordinated delivery of interventions to ensure patient-centered care.

- Includes a defining set of theory-driven constructs relevant to integrated implementation of chronic disease management interventions and activities within clinical settings.

\section{Introduction}

Collaboration between public health and primary care is seen as an opportunity to promote health at the individual and community levels [1-3]. Integrated implementation of patient care interventions and activities can support primary care clinics in improving efficiency of clinic workflows and coordinating delivery of patient-centered preventive care $[4,5]$. Integrated implementation also may support longer-term outcomes, including clinic institutionalization of health promotion practices and cost savings $[6,7]$. Public health partners can play an important role in supporting the implementation of these practices in primary care settings.

In 2015, the Centers for Disease Control and Prevention (CDC) funded the Colorectal Cancer Control Program (CRCCP), which is based on a health systems change model that promotes integrating public health and primary care to improve population health; specifically, to increase colorectal cancer (CRC) screening among medically underserved populations (Fig. 1) [8].

CDC funded 30 CRCCP program sites (hereafter referred to as programs) that partner with primary care clinics (hereafter referred to as clinic partners) to implement evidence-based interventions (EBIs) recommended by the Community Preventive Services Task Force in The Community Guide [9] coupled with other supporting activities (SAs) to increase the uptake of CRC screening. The CRCCP DP15-1502 was funded for 5 years from 2015-2020. Participating clinic partners selected up to four EBIs prioritized by CDC-patient reminders, provider reminders, provider assessment and feedback, and reducing structural barriers to screening-and other SAs to implement based on clinic priorities and feasibility. SAs include implementing community health worker-led activities, patient navigation, health information technology, professional development, and small media. CRCCP programs and partners with relevant expertise, such as the American Cancer Society and the State Primary Care Association, provide technical support to implement these activities. Because the CRCCP is focused on health systems change-such as 
improving workflows and electronic health record (EHR) systems to incorporate EBIs/SAs so that they are sustainable-the opportunity exists to integrate the implementation of EBIs and SAs to promote not just CRC screening but also other screening and/or chronic disease management activities. Intended outcomes of this integrated approach to implementing EBIs and SAs include improved efficiency of clinic workflow, improved coordination of patient care, increased uptake of CRC screening, and improved patient outcomes.

This study aimed to examine CRCCP clinics where EBIs and SAs to promote CRC screening were integrated with other screening and chronic disease management activities and to identify practices facilitating this integration. CDC intends to use the study findings for CRCCP implementation. Findings could also potentially be used by other organizations involved in promoting CRC screening and management of other chronic diseases. Lessons learned also may support cancer screening integration efforts among other chronic disease programs.

\section{Methods}

We used the Consolidated Framework for Implementation Research (CFIR) [10] to structure our approach to identify factors that support integrated implementation of EBIs and SAs, focusing on characteristics of the inner setting (clinics, in this context)-features of structural, political, and cultural context. Using the CFIR, we conducted a literature review to identify key constructs relevant to integrated implementation that aligned with CFIR inner setting constructs: readiness for implementation, structural characteristics, and networks and communication. Our literature review yielded four key integrated implementation constructs (Table 1) that guided data collection and analysis efforts.

Our primary evaluation question was, "What factors support integrated implementation of EBIs and SAs to promote CRC screening with other screening and chronic disease management activities within primary care clinics?" We developed additional evaluation questions (see Additional file 1) related to each of the key constructs in Table 1. An overview of our methodological approach is provided in Fig. 2 and further detail about site selection, data collection, and analysis are provided below.

\section{Site Selection}

We purposively selected three CRCCP programs: Kentucky Department of Public Health; Rhode Island Department of Health; and Washington State Department of Health. We also included the Nebraska Department of Health and Human Service's CRC program, which had been a CRCCP awardee funded from 2009-2015. Although Nebraska was not part of the 2015-2020 CRCCP, they maintained program efforts with state funds. These four programs participated in the CRCCP Learning Collaborative, an innovative initiative to develop and apply a standardized approach to evaluate the implementation, effectiveness, cost, and cost-effectiveness of multicomponent interventions to inform future scale-up of these interventions [7]. Based on cost-effectiveness analyses, all four programs exhibited partnerships with clinics to integrate CRC EBIs and SAs implementation. 


\section{Data Collection}

For each selected program, we interviewed staff, clinic partners, and implementation partner organizations (e.g., non-clinic partners funded to provide technical assistance to clinics). The four theorybased constructs-governance structure, information sharing, funding environment, and leadership support-and evaluation questions informed the development of unique interview guides for each of the three participant roles. We selected these participant types to gather input from multiple perspectives. Sample interview questions are provided in Additional file 2.

Prior to primary data collection, we reviewed secondary data for each program, such as budgets and survey findings. Secondary data were not available for Nebraska because they were not receiving CRCCP funds at the time of our interviews. To gather contextual information about each program before initiating interviews, we spoke with CDC staff who provided tailored technical assistance directly to the three selected CRCCP programs.

We obtained verbal consent for interviews from each participant. Institutional Review Board approval was not required for this data collection because it did not constitute human subjects research. In total, 23 individuals, including representatives from one clinic partner location per program, participated in semistructured telephone interviews (Table 2) using unique interview guides conducted between February and May 2019. Interviews were audio-recorded, with consent, and transcribed for analysis. The Standards for Reporting Qualitative Research checklist guided our qualitative methods and reporting of results (see Additional file 3) [25].

\section{Analysis}

Prior to analysis, we developed a coding dictionary based on our evaluation questions (see Additional file 4). A team of four analysts pilot-coded two interview transcripts using the qualitative software NVivo QSR 11.0. The team then met to develop consensus regarding refinement and application of the coding framework. Four interviews (20\%) were double coded-independently coded by two analysts-and analysts achieved a Kappa coefficient of 0.8 or higher for each. The remaining interviews were divided evenly among the four analysts and independently coded. Following coding, analysts reviewed code reports to identify program-specific emerging themes and recorded these themes in summary tables that included a description of each theme, illustrative quotes supporting the theme, and the interviewee role for each quote. Analysts convened and reviewed all theme tables and identified cross-cutting emergent themes, which were themes that emerged across at least two programs.

\section{Results}

Brief descriptions of clinic partner approaches to integrated implementation of CRCCP activities are provided in Additional file 5. In the following sections, we present our results based on the four guiding integrated implementation constructs. These results are summarized in Figure 3. 


\section{Funding Environment}

The clinic partners received funding from the CRCCP programs, typically to support start-up and ongoing costs associated with implementing the CRCCP within their sites. Two aspects of the funding environment were identified as facilitating integrated implementation: (1) coordination of funding by awardees across multiple chronic disease programs to support consolidated application processes for clinic partners, and (2) contracting with expert implementation partners to provide training and technical assistance to clinic partners that emphasized integrated implementation.

Participants discussed programs providing braided funding-a process that involves coordinating separate funding streams from multiple programs, such as CRCCP and the National Breast and Cervical Cancer Early Detection Program (NBCCEDP) -to pay for common activities such as patient navigation across programs, provider reminders and patient reminders (e.g., reminders for breast, cervical, and colorectal cancer screening). However, each funding stream is kept separate so programs can track requirements and outcomes. For example, program staff discussed developing funding opportunity announcements for clinic partners that braided funding streams from multiple programs. This approach enabled clinic partners to consolidate their funding applications and reporting processes while tracking distinct activities and outcomes for each funding stream. Participants also reported that by braiding funding from multiple chronic disease programs, clinic partners could submit a single funding application and receive a larger amount of funding that could be used to integrate implementation efforts across multiple chronic diseases. For instance, participants reported the use of braided funding to support patient navigation staff who coordinate screening and follow-up for CRC, breast cancer, and cervical cancer.

"The [health department's] women's cancer screening and colorectal had patient navigation contracts with all the [Federally Qualified Health Centers] throughout the state and in order to get the FQHCs to agree to do the colorectal, right from the beginning she integrated the contracts so we essentially were doubling the money that we were offering to them and it was an all or nothing kind of thing."

\section{- Program staff}

"[We aim to] present different contract options which combine all the different funding sources...in an integrated way, approaching them with this single menu of different options collectively...versus one of us [from the health department] approaching them one month and then another one approaching them 3 months later."

- Program staff

"[Braided funding supports] staff time and the training that we need for our staff to do the outreach for all of the cancer screenings."

- Clinic staff 
Participants also described how technical assistance and training, provided by expert implementation partners, facilitated integrated implementation. For example, implementation partners assisted clinics in adapting EHR or other referral systems to integrate CRC screening with existing referral systems for breast cancer screening such as mammography.

"[Implementation partner agency] is our partner in understanding how to look at [clinic] practice flows and how to coordinate, integrate, align the work we do.... They say, 'Okay, you really need to work on your electronic referrals [for screening]. Let's look at how you're doing that with mammograms. Let's look at how you're doing that with colonoscopy."'

- Program staff

"We strongly encourage [clinic partners] to consider how their efforts could be better integrated with their other programs and activities in their clinic systems. For example, when they describe [clinic] workflows to us on these technical assistance calls, we try to prompt them to consider how these efforts may impact other efforts ongoing in their clinics, other screening activities...if they're going to look at, for example, whether or not a patient is due for colorectal cancer [screening as part of workflow processes], seeing if there are opportunities in their other cancer screening activities and workflows."

- Implementation partner staff

\section{Governance Structure}

Effective team-based care, a factor related to governance structure, ensured that CRC screening was integrated into clinic practice as part of comprehensive, coordinated patient care. For example, some clinics used "health hubs" comprised of clinic staff from CRCCP, WISEWOMAN, and NBCCEDP to implement coordinated EBIs across programs. Participants reported that effective teaming supports a shared sense of responsibility for providing comprehensive (such as multiple health topics), coordinated patient care. For example, participants described training all clinic staff-such as patient registration staff, lab technicians, and nurses-to address CRC and other health conditions with each patient encounter. Workforce development (e.g., learning collaboratives) also included clinic staff representing multiple chronic disease prevention areas. Additionally, participants described the integration of CRC screening with other services (e.g., coordinated patient enrollment with WISEWOMAN and NBCCEDP; coordinated patient and provider reminders) as being consistent with their commitment to applying a Patient Centered Medical Home (PCMH) model.

"So, every clinical person from our lab person to our [patient] registration staff to every nurse [and] medical assistant understands that they're required to address all of these [health topics] with every patient. It's just the way we train them when they come in...it's the way we do business."

- Clinic staff 
"Going back to the PCMH [model] of having all staff [perform at] the highest ability that they're able to. So, our frontline, our medical assistants, our front-desk staff are very involved and very engaged in these management activities, cancer screening activities."

- Clinic staff

"We have a team medical assistant [who] is able to follow up on closing the loop to patients about, 'Hey, I see you haven't done this,' or 'Your [test]was high. We need you to come back in or follow up on those things.' And then the RN is able to really take the time and educate the patients on different dietary concerns, different ways to manage whatever specific chronic condition that they have."

- Clinic staff

\section{Information Sharing}

Access to and sharing of accurate patient information, including EHR data, were identified as other factors supporting integrated implementation of CRC screening. Identifying patients who are due for multiple preventive screenings, including CRC, was an example shared by participants. Once patients could be identified, referrals could be made and follow-up actions-such as appointment scheduling and confirming screening completion-could be carried out.

Participants indicated that clinic staff, particularly patient navigators and care coordinators, rely on the availability of accurate EHR reports to identify patients for screening and/or diagnostics for multiple chronic disease conditions. Clinic staff emphasized that the utility of the EHR data in supporting integrated implementation is contingent on data accuracy.

"The challenges we face with $\mathrm{CRC}$, breast cancer, and cervical reporting [are] the same challenges we face with everything else. Making sure [EHR data] are entered correctly and data validation."

- Clinic staff

Aside from EHRs, participants identified data dashboards and meetings of the quality improvement team as strategies for sharing information that facilitated integrated implementation. Electronic dashboards presented summary metrics on multiple cancer screenings in real-time for each provider and their respective patients. Through data sharing and making comparisons between physicians that invite friendly competition, the dashboards promote action on multiple conditions that contribute to integrated implementation. Similarly, data sharing among quality improvement (QI) teams promotes a collective understanding of where clinics stand on delivery of health promotion activities that can foster understanding of opportunities to potentially improve these metrics through integrated implementation.

"All of our staff have access to the provider dashboard, which is updated once a month and that shows where their particular provider is and what the [clinic] average is and then... they can go and look at any 
other provider...it's just starting with the cancer screening metric, but eventually we'll put all of our metrics on that...it will give them more of a real-time feel of where they're at."

- Clinic staff

"We also...had monthly quality improvement meetings, where all of the clinic's leadership and the QI department got together, and we talked about things that we are working on, and things that could potentially be shared...beyond just cancer, or beyond just diabetes care, or whatever thing we were talking about."

- Clinic staff

\section{Leadership Support}

Clinic leadership plays a primary role in promoting integrated implementation by setting and reinforcing expectations. Participants indicated that strong and ongoing support from health system and clinic leadership establishes an expectation for integrating CRC EBIs and SAs within the clinic practice and incorporating CRC screening efforts with other chronic disease activities. Additionally, leaders are crucial in encouraging staff from across the clinic team to support these activities.

"Leadership support is critical.... It's evident, if you see the [screening] numbers of the teams that have the leadership support and the ones from the team that didn't [have leadership support], it's night and day."

- Implementation partner staff

"I'm the clinic manager and so I set the tone for the sense that the evidence-based interventions are important. We need to integrate them and so you talk about it, you bring it up frequently. As a group, we collectively talk about what we think works for us and what doesn't work for us."

- Clinic staff

\section{Discussion}

Our study examined the CRCCP, a public health program implemented in primary care clinics, to identify factors facilitating the integration of $\mathrm{EBI}$ and $\mathrm{SA}$ implementation with other screening and chronic disease management activities. Using the CFIR helped focus identification of factors that support integrated implementation of EBls and SAs, including funding environment, governance, information sharing, and leadership.

We found that integration efforts in clinics were supported by programs consolidating their chronic disease funding into single contracts for partner clinics, rather than providing separate, "siloed" contracts for individual health conditions. In the CRCCP, this funding approach presents an opportunity for more efficient use of public health funding for delivering coordinated cancer screenings and other disease 
management interventions to support more holistic, patient-centered care. Efficiencies are also achieved when clinic staff respond to a single, consolidated funding application rather than multiple applications. And the pooled funding provides both programs and clinics flexibility to leverage funds and share overhead costs, offering the opportunity to achieve more with their awarded funds [26]. At the program level, consolidated funding also supports efficiency by streamlining delivery of training and technical assistance to a smaller number of funding recipients; meaning that more in-depth support can be provided to trainees.

At the clinic level, a team-based approach was found to support more integrated care for a patient, including for CRC screening. Teams of clinicians are likely able to determine how best to integrate CRC screening efforts-such as identifying patients who are due for screening and determining how to deliver a reminder to a provider-into existing clinic workflows. This is consistent with coordinated delivery of interventions to ensure patient-centered care, which can ultimately lead to improved patient outcomes and quality of life, as demonstrated through the PCMH model $[27,28]$. Patient-centered care also has shown promise toward reducing health care costs [29].

EHR systems, a reservoir of patient information, also were found to be important to integrated implementation. Although investing in functional EHR systems can be costly, they are recognized as essential to enable optimal, integrated, patient-centered care because they allow for abstraction of accurate clinical information. In 2011, the Centers for Medicare \& Medicaid Services established an EHR incentive program to reward meaningful use of certified EHR systems to improve quality of care [30]. Since then, there has been a national push for health systems to adopt EHRs to support clinical practice transformation. Meaningful use of EHRs has been associated with quality improvement in Federally Qualified Health Centers (FQHCs) [31]. In 2012, 90\% of FHQCs had adopted an EHR and about one-third had met core requirements for meaningful use [32]. The findings from our study indicate that EHRs also can help facilitate integrated implementation of EBIs to promote cancer and other chronic disease screenings. For example, once developed, data dashboards that display provider performance metrics for CRC screening can be replicated and/or expanded to produce monitoring data for other cancer or chronic disease screenings, placing patients at the center of care provided by multiple public health programs. Additionally, EBIs that can be enabled through the EHR system, such as automated patient and provider reminders or performance metrics to populate dashboards, may be more sustainable. Once these strategies are built into EHR systems, significant efficiencies could be achieved.

Finally, leaders' expectations for integrated implementation sets the tone for other staff and directs practice. CRC champions, individuals serving as internal advocates for screening, help maintain a focus on screening and were found to be associated with greater screening rate increases in CRCCP clinics [8]. Champions have been found to contribute to improved public health outcomes in many areas and efforts to sustain and support them as part of the CRCCP is critical [33]. Therefore, leadership support is essential for clinic champions to effectively promote and sustain integrated implementation. 
Our findings highlight elements and practices of integrated implementation that can support clinics in achieving desired short-term outcomes, including efficient, coordinated delivery of interventions to ensure patient-centered care, which can ultimately lead to improved patient outcomes and quality of life as well as reduced health care costs $[27,28]$.

CDC, through the CRCCP Learning Collaborative, is working with programs and clinic partners to systematically evaluate the cost and cost-effectiveness of combined implementation of EBIs for cancer screenings [7]. Lessons learned from the integrated implementation platform for CRC screening through the CRCCP might be applied to enhance other public health and primary care partnership programs, such as CDC's National Breast and Cervical Cancer Early Detection Program. For example, findings might be applied to inform the structure of public health department partnerships with clinic and non-clinic partners; inform the nature of training and technical assistance provided to primary care clinics; encourage early efforts to seek leadership buy-in to setting the stage for integration; and reiterate the value of capturing and sharing high-quality data to support integrated programs.

There are certain limitations for our findings. First, because the study was qualitative and engaged a subset of current and former CRCCP programs and their primary care clinic partners, these findings are not generalizable to all CRCCP programs or primary care clinic sites. Second, the findings reflect a relatively small number of participants included in the data collection. Third, this study was framed around exploration of four theory-driven constructs. Future analysis that incorporates a broader set of constructs may generate additional insights regarding factors that support integrated implementation of interventions for multiple conditions within primary care. Finally, we did not track outcomes in this analysis but plan to engage in such assessments in future analyses.

\section{Conclusion}

In this study, we identify factors, at the CRCCP program and clinic levels that support integrated implementation of EBIs and SAs within clinic settings to promote CRC screening and screening/management of other chronic diseases. We present our findings within the frame of four theory-based implementation constructs. The findings provide insights into how public health programs and primary care clinics can collectively support integrated implementation of interventions and activities into clinic workflows to support efficient, coordinated delivery of patient-centered care. The next step is for further research to explore the impact of these public health and primary care partnerships and related activities on patient and program outcomes.

\section{Abbreviations}

CDC: Centers for Disease Control and Prevention

CFIR: Consolidated Framework for Implementation Research

CRCCP: Colorectal Cancer Control Program 
EBIs: evidence-based interventions

EHR: electronic health record

FQHC: Federally Qualified Health Center

PCMH Patient Centered Medical Home

SAs: $\quad$ supporting activities

\section{Declarations}

\section{Acknowledgements}

We would like to express appreciation to all the individuals who participated in the interviews for this project, including staff from Rhode Island (the Rhode Island Department of Health, WellOne Primary Medical \& Dental Care, the Rhode Island Health Center Association), Nebraska (the Nebraska Department of Health and Human Services, Nebraska Urban Indian Health Center, South Heartland District Health Department, Partnership for a Healthy Lincoln, Nebraska Association of Local Health Directors), Washington (the Washington Department of Health, Valley View Health Center, Washington Association for Community Health, the University of Washington), and Kentucky (Kentucky Cabinet for Health and Family Services, Juniper Health, the American Cancer Society - North Central Region of Kentucky, and the Kentucky Regional Extension Center).

\section{Authors' Contributions}

All authors contributed to the development of the research and evaluation questions. CS and LA developed the interview guides, with feedback from SS, SH, AD, FT, DS and SM. CS, LA, and SH conducted the interviews. LA, CS, DS, and SM conducted the qualitative coding and performed the thematic analysis. CS drafted and revised the manuscript based on comments from the coauthors. All authors read and approved the final manuscript.

\section{Authors' Information}

Not applicable.

\section{Funding}

Funding support was provided by the Centers for Disease Control and Prevention (CDC) (Contract No. 200-2014-61263 Task 4) to RTI International. The findings and conclusions in this report are those of the authors and do not necessarily represent the official position of the CDC. 


\section{Availability of Data and Materials}

The qualitative data generated and/or analyzed during the current study are not publicly available because they were generated in interviews conducted by the research team, with the expectation that participant identity would be kept confidential.

\section{Ethics Approval and Consent to Participate}

The RTI Institutional Review Board determined that this study did not constitute human subjects research and therefore did not require review. Verbal consent to participate was obtained from all individuals who participated in interviews.

\section{Consent for Publication}

Consent for a de-identified summary of findings was obtained from individuals who participated in the interviews.

\section{Competing Interests}

The authors declare that they have no competing interests.

\section{Author Details}

${ }^{1}$ RTI International, 3040 E. Cornwallis Road, Durham, NC 27709, USA. 2 Division of Cancer Prevention and Control, National Center for Chronic Disease Prevention and Health Promotion, Centers for Disease Control and Prevention.

\section{References}

1. Donaldson MS, Yordy KD, Lohr KN, Vanselow NA, editors. Primary care: America's health in a new era. Washington, DC: National Academies Press. 1996.

2. Linde-Feucht $\mathrm{S}$, Coulouris N. Integrating primary care and public health: a strategic priority. Am J Prev Med 2012; 42(6 Suppl 2):S95-6.

3. Institute of Medicine, Committee on Integrating Primary Care and Public Health. Primary care and public health: Exploring integration to improve population health. Washington, DC2012.

4. Sekhri N, Feachem R, Ni A. Public-private integrated partnerships demonstrate the potential to improve health care access, quality, and efficiency. Health Aff (Millwood) 2011; 30(8):1498-507. 
5. Koh HK, Tavenner M. Connecting care through the clinic and community for a healthier America. Am J Public Health 2012; 102 Suppl 3:S305-7.

6. Shade SB, Kevany S, Onono M, Ochieng G, Steinfeld RL, Grossman D, et al. Cost, cost-efficiency and cost-effectiveness of integrated family planning and HIV services. AIDS 2013; 27 Suppl 1:S87-92.

7. Subramanian S, Hoover S, Tangka FKL, DeGroff A, Soloe CS, Arena LC, et al. A conceptual framework and metrics for evaluating multicomponent interventions to increase colorectal cancer screening within an organized screening program. Cancer 2018; 124(21):4154-62.

8. DeGroff A, Sharma K, Satsangi A, Kenney K, Joseph D, Ross K, et al. Increasing Colorectal Cancer Screening in Health Care Systems Using Evidence-Based Interventions. Prev Chronic Dis 2018; 15:E100.

9. The Community Guide. Cancer Atlanta, GA: The Community Guide; 2018 [cited 20193 December]; Available at: https://www.thecommunityguide.org/topic/cancer.

10. Damschroder LJ, Aron DC, Keith RE, Kirsh SR, Alexander JA, Lowery JC. Fostering implementation of health services research findings into practice: a consolidated framework for advancing implementation science. Implement Sci 2009; 4(50):1-15.

11. Suter E, Oelke ND, Adair CE, Armitage GD. Ten key principles for successful health systems integration. Healthc Q 2009; 13 Spec No(Spec No):16-23.

12. Strandberg-Larsen M, Krasnik A. Measurement of integrated healthcare delivery: a systematic review of methods and future research directions. Int J Integr Care 2009; 9:e01.

13. McGinnis T, Crawford M, Somers SA. A state policy framework for integrating health and social services. Issue Brief (Commonw Fund) 2014; 14:1-9.

14. DeSalvo KB, Wang YC, Harris A, Auerbach J, Koo D, O'Carroll P. Public health 3.0: a call to action for public health to meet the challenges of the 21 st Century. Prev Chronic Dis 2017; 14:E78.

15. Nicholson C, Jackson C, Marley J. A governance model for integrated primary/secondary care for the health-reforming first world-results of a systematic review. BMC Health Serv Res 2013; 13:528.

16. Naylor $\mathrm{C}$, Alderwick H, Honeyman M. Acute hospitals and integrated care: from hospitals to health systems. London, UK: The King's Fund, 2015.

17. Struijs JN, Drewes HW, Stein KV. Beyond integrated care: challenges on the way towards population health management. Int J Integr Care 2015; 15:e043.

18. Quigley L, Lacombe-Duncan A, Adams S, Hepburn CM, Cohen E. A qualitative analysis of information sharing for children with medical complexity within and across health care organizations. BMC Health Serv Res 2014; 14:283.

19. Nieuwboer MS, van der Sande R, van der Marck MA, Olde Rikkert MGM, Perry M. Clinical leadership and integrated primary care: A systematic literature review. Eur J Gen Pract 2019; 25(1):7-18.

20. Psek W, Davis FD, Gerrity G, Stametz R, Bailey-Davis L, Henninger D, et al. Leadership Perspectives on Operationalizing the Learning Health Care System in an Integrated Delivery System. EGEMS (Wash DC) $2016 ; 4(3): 1233$. 
21. deGruy FV, 3rd. Integrated care: tools, maps, and leadership. J Am Board Fam Med 2015; 28(Suppl 1):S107-10.

22. Hargett CW, Doty JP, Hauck JN, Webb AM, Cook SH, Tsipis NE, et al. Developing a model for effective leadership in healthcare: a concept mapping approach. J Healthc Leadersh 2017; 9:69-78.

23. Taplin SH, Foster MK, Shortell SM. Organizational leadership for building effective health care teams. Ann Fam Med 2013; 11(3):279-81.

24. Trastek VF, Hamilton NW, Niles EE. Leadership models in health care-a case for servant leadership. Mayo Clin Proc 2014; 89(3):374-81.

25. O'Brien BC, Harris IB, Beckman TJ, Reed DA, Cook DA. Standards for reporting qualitative research: a synthesis of recommendations. Acad Med 2014; 89(9):1245-51.

26. Ensign K, Kain JC. Braiding and Layering funding: doing more with what we have. J Public Health Manag Pract 2020; 26(2):187-91.

27. Stange KC, Nutting PA, Miller WL, Jaen CR, Crabtree BF, Flocke SA, et al. Defining and measuring the patient-centered medical home. J Gen Intern Med 2010; 25(6):601-12.

28. Epstein RM, Fiscella K, Lesser CS, Stange KC. Why the nation needs a policy push on patient-centered health care. Health Aff (Millwood) 2010; 29(8):1489-95.

29. Liang H, Tao L, Ford EW, Beydoun MA, Eid SM. The patient-centered oncology care on health care utilization and cost: A systematic review and meta-analysis. Health Care Manage Rev 2018.

30. Promoting Interoperability Programs. 2020, September 18; Available at: https://www.cms.gov/Regulations-and-Guidance/Legislation/EHRIncentivePrograms.

31. Kern LM, Edwards AM, Pichardo M, Kaushal R. Electronic health records and health care quality over time in a federally qualified health center. J Am Med Inform Assoc 2015; 22(2):453-8.

32. Jones EB, Furukawa MF. Adoption and use of electronic health records among federally qualified health centers grew substantially during 2010-12. Health Aff (Millwood) 2014; 33(7):1254-61.

33. Durlak JA, DuPre EP. Implementation matters: a review of research on the influence of implementation on program outcomes and the factors affecting implementation. Am J Community Psychol 2008; 41(3-4):327-50.

\section{Tables}

Table 1. Guiding Consolidated Framework for Implementation Research (CFIR) and integrated implementation construct descriptions 


\begin{tabular}{|c|c|c|}
\hline $\begin{array}{l}\text { CFIR Construct and } \\
\text { Definition }\end{array}$ & $\begin{array}{l}\text { Integrated } \\
\text { Implementation } \\
\text { Construct }\end{array}$ & Integrated Implementation Construct Description \\
\hline $\begin{array}{l}\text { Readiness for } \\
\text { Implementation: } \\
\text { Available Resources }\end{array}$ & $\begin{array}{l}\text { Funding } \\
\text { environment }\end{array}$ & $\begin{array}{l}\text { Integrated health and social services are supported by } \\
\text { financing mechanisms that fund services and allow } \\
\text { braiding or blending of funds with flexibility in the use } \\
\text { of funds to achieve population health goals [ } 3,11-14] \text {. } \\
\text { Integrated services also may be supported by partner } \\
\text { agencies that receive funding to provide training and }\end{array}$ \\
\hline $\begin{array}{l}\text { The level of resources } \\
\text { dedicated for } \\
\text { implementation and } \\
\text { on-going operations, } \\
\text { including money, } \\
\text { training, education, } \\
\text { physical space, and } \\
\text { time. }\end{array}$ & & $\begin{array}{l}\text { technical assistance to assist clinics to adapt clinical } \\
\text { workflows. }\end{array}$ \\
\hline $\begin{array}{l}\text { Networks and } \\
\text { Communication }\end{array}$ & $\begin{array}{l}\text { Governance } \\
\text { structure }\end{array}$ & $\begin{array}{l}\text { Cooperation between and within organizations to } \\
\text { support integrated health care delivery requires } \\
\text { governance structures that promote coordination, joint } \\
\text { planning, shared priorities, and a common } \\
\text { understanding of accountability among staff [11, 15- } \\
\text { 17]. }\end{array}$ \\
\hline $\begin{array}{l}\text { The nature and quality } \\
\text { of webs of social } \\
\text { networks and the } \\
\text { nature and quality of } \\
\text { formal and informal } \\
\text { communications } \\
\text { within an } \\
\text { organization. }\end{array}$ & $\begin{array}{l}\text { Information } \\
\text { sharing }\end{array}$ & $\begin{array}{l}\text { Information flow in a clinical setting is necessary for } \\
\text { integrated health care delivery and is supported by the } \\
\text { presence of a secure, accessible platform for storing } \\
\text { and sharing health care information, consistent } \\
\text { documentation, and a structured plan to facilitate } \\
\text { seamless communication among health system care } \\
\text { providers }[11,13,18] \text {. }\end{array}$ \\
\hline $\begin{array}{l}\text { Readiness for } \\
\text { Implementation: } \\
\text { Leadership } \\
\text { Engagement }\end{array}$ & $\begin{array}{l}\text { Leadership } \\
\text { support }\end{array}$ & $\begin{array}{l}\text { Leadership recognition of the importance of integration } \\
\text { and provision of tangible support and resources are } \\
\text { influential in adoption and implementation of care } \\
\text { integration [19-24]. }\end{array}$ \\
\hline $\begin{array}{l}\text { Commitment, } \\
\text { involvement, and } \\
\text { accountability of } \\
\text { leaders and managers } \\
\text { with the } \\
\text { implementation. }\end{array}$ & & \\
\hline
\end{tabular}

Table 2. Interviews by program site ${ }^{\mathrm{a}}$ and respondent type and site 


\begin{tabular}{|lllll|}
\hline State & $\begin{array}{l}\text { Program } \\
\text { Staff }\end{array}$ & $\begin{array}{l}\text { Clinic Partner } \\
\text { Staff }\end{array}$ & $\begin{array}{l}\text { Implementation Partner } \\
\text { Staff }\end{array}$ & $\begin{array}{l}\text { Total } \\
\text { Interviewees }\end{array}$ \\
\hline Kentucky & 2 & 2 & 2 & 6 \\
\hline Nebraska & 2 & 2 & 2 & 6 \\
\hline $\begin{array}{l}\text { Rhode } \\
\text { Island }\end{array}$ & 2 & 2 & 2 & 6 \\
\hline Washington & 2 & 1 & 2 & 5 \\
\hline Total & & & & 23 \\
\hline
\end{tabular}

a Kentucky Department of Public Health, Nebraska Department of Health and Human Services, Rhode Island Department of Health, Washington State Department of Health

\section{Supplementary Information}

Additional File 1. Supplemental Appendix 1. Primary Evaluation Questions. This document presents additional evaluation questions related to each of the key constructs in Table 1.

Additional File 2. Supplemental Appendix 2. Sample Interview Questions (Table of sample questions related to each construct). This document presents sample questions for the qualitative interviews.

Additional File 3. Supplemental Appendix 3. Standards for Reporting Qualitative Research checklist. This document contains the completed Standards for Reporting Qualitative Research checklist for the reported study.

Additional File 4. Supplemental Appendix 4. Coding Structure (23 Codes developed based on evaluation questions). This document provides a coding dictionary based on the evaluation questions.

Additional File 5. Supplemental Appendix 5. Brief Description of Clinic Partner Integrated Implementation Approaches, by Site. This document provides brief descriptions of clinic partner approaches to integrated implementation of CRCCP activities.

Additional file 1. Primary evaluation questions 


\begin{tabular}{|c|c|}
\hline & Primary Evaluation Questions \\
\hline \multirow[t]{4}{*}{$\begin{array}{l}\text { Governance } \\
\text { structure }\end{array}$} & $\begin{array}{l}\text { How are programs and clinics structured to support integrated implementation } \\
\text { of EBls and SAs? }\end{array}$ \\
\hline & $\begin{array}{l}\text { How are health teams being used as part of integrated implementation of EBls } \\
\text { and SAs? }\end{array}$ \\
\hline & $\begin{array}{l}\text { What does integrated implementation of EBls and SAs look like in terms of } \\
\text { clinic workflow? }\end{array}$ \\
\hline & $\begin{array}{l}\text { What activities are conducted at the clinic to facilitate integration of EBIs and } \\
\text { SAs implementation with clinic processes? }\end{array}$ \\
\hline \multirow{2}{*}{$\begin{array}{l}\text { Leadership } \\
\text { support }\end{array}$} & How is clinic leadership supporting integrated implementation of EBIs and SAs? \\
\hline & How is program leadership supporting integration? \\
\hline \multirow[t]{3}{*}{$\begin{array}{l}\text { Funding } \\
\text { environment }\end{array}$} & $\begin{array}{l}\text { How are multiple lines of funding (e.g., CRC, NBCCEDP) to clinics coordinated to } \\
\text { support integrated implementation of EBls and SAs? }\end{array}$ \\
\hline & $\begin{array}{l}\text { To what extent are the programs and/or their partners (clinic and } \\
\text { implementation partners) sharing resources (monetary and other) to support } \\
\text { integrated implementation of EBls and SAs? }\end{array}$ \\
\hline & $\begin{array}{l}\text { In what ways do programs incentivize or encourage integrated implementation } \\
\text { of EBls and SAs at the clinic level? }\end{array}$ \\
\hline \multirow[t]{3}{*}{$\begin{array}{l}\text { Information } \\
\text { sharing }\end{array}$} & $\begin{array}{l}\text { How is information shared within clinics and health systems to support } \\
\text { integrated implementation of EBls and SAs? }\end{array}$ \\
\hline & $\begin{array}{l}\text { What challenges and benefits have clinics encountered in coordinating data } \\
\text { entry and reporting around integrated implementation of EBls and SAs? }\end{array}$ \\
\hline & $\begin{array}{l}\text { How does a clinic's EHR system facilitate/hinder efforts to integrate } \\
\text { implementation of EBIs/SAs? }\end{array}$ \\
\hline
\end{tabular}

Note: NBCCEDP, National Breast and Cervical Cancer Early Detection Program; CRC, colorectal cancer; EBI, evidence-based interventions; EHR, electronic health record; SAs, supporting activities.

Additional file 2. Sample interview questions (table of sample questions related to each construct) 


\begin{tabular}{|c|c|}
\hline Construct & Sample Interview Questions \\
\hline \multirow[t]{4}{*}{$\begin{array}{l}\text { Governance } \\
\text { structure }\end{array}$} & $\begin{array}{l}\text { In what ways does staffing structure at the health department support } \\
\text { integrated implementation of CRCCP activities with those of other cancer or chronic } \\
\text { disease area programs? }\end{array}$ \\
\hline & $\begin{array}{l}\text { In what ways does staffing structure at the clinic support implementation of } \\
\text { EBIs across multiple cancer or chronic disease area programs? }\end{array}$ \\
\hline & $\begin{array}{l}\text { To what extent is integrated implementation reflected in clinic standard } \\
\text { operating procedures? }\end{array}$ \\
\hline & $\begin{array}{l}\text { Based on your experience, what do programs or clinics need in terms of } \\
\text { infrastructure to be able to successfully integrate implementation of EBIs? }\end{array}$ \\
\hline \multirow[t]{4}{*}{$\begin{array}{l}\text { Leadership } \\
\text { support }\end{array}$} & $\begin{array}{l}\text { In what ways does your health department leadership support integration of } \\
\text { CRCCP with other cancer or chronic disease area programs? }\end{array}$ \\
\hline & $\begin{array}{l}\text { In what ways does your health department leadership support integrated } \\
\text { implementation of EBls at the clinic level? }\end{array}$ \\
\hline & $\begin{array}{l}\text { In what ways does the health department support integrated implementation of } \\
\text { EBls at your clinic? }\end{array}$ \\
\hline & . In what ways is clinic leadership supporting integrated implementation of EBIs? \\
\hline \multirow[t]{5}{*}{$\begin{array}{l}\text { Funding } \\
\text { environment }\end{array}$} & $\begin{array}{l}\text { To what extent are multiple lines of funding (e.g., colon cancer, breast, cervical, } \\
\text { heart disease, and diabetes screenings) to clinic sites coordinated to support } \\
\text { integrated implementation of EBls? }\end{array}$ \\
\hline & $\begin{array}{l}\text { In what ways does the health department incentivize or encourage integrated } \\
\text { implementation at the clinic level? }\end{array}$ \\
\hline & $\begin{array}{l}\text { How have you used funding from the health department to support integrated } \\
\text { implementation of EBls? }\end{array}$ \\
\hline & $\begin{array}{l}\text { What influence do policies and/or incentives (national quality incentive } \\
\text { programs) have on improvement of integrated implementation of EBIs? }\end{array}$ \\
\hline & $\begin{array}{l}\text { Does the health department provide your organization with funding for your role } \\
\text { in supporting integrated implementation of EBIs in their clinic partners? }\end{array}$ \\
\hline \multirow[t]{3}{*}{$\begin{array}{l}\text { Information } \\
\text { sharing }\end{array}$} & $\begin{array}{l}\text { How is programmatic information, such as clinical or financial information, } \\
\text { shared between your program and other chronic disease programs with which you're } \\
\text { collaborating at the health department? }\end{array}$ \\
\hline & $\begin{array}{l}\text { How is information shared within clinics and health systems to support } \\
\text { integrated implementation of EBls? }\end{array}$ \\
\hline & $\begin{array}{l}\text { Thinking about the logistics of documentation-such as reporting requirements } \\
\text { to the health department, HRSA, your health system, or other entities-have there been } \\
\text { any challenges in terms of documentation or data reporting due to integrated } \\
\text { implementation of EBIs? Any benefits? }\end{array}$ \\
\hline
\end{tabular}

Note: CRCCP, Colorectal Cancer Control Program; EBIs, evidence-based interventions; HSRA, Health Services Research Administration. 
Additional file 3. Completed Standards for Reporting Qualitative Research Checklist

\section{Standards for Reporting Qualitative Research (SRQR)*}

http://www.equator-network.org/reporting-guidelines/srqr/ 


\section{Title and abstract}

Title - Concise description of the nature and topic of the study Identifying the study as qualitative or indicating the approach (e.g., ethnography, grounded theory) or data collection methods (e.g., interview, focus group) is recommended

Abstract - Summary of key elements of the study using the abstract format of the intended publication; typically includes background, purpose, methods, results, and conclusions

\section{Introduction}

Problem formulation - Description and significance of the problem/phenomenon studied; review of relevant theory and empirical work; problem statement

Purpose or research question - Purpose of the study and specific objectives or questions

\section{Methods}

Qualitative approach and research paradigm - Qualitative approach (e.g., ethnography, grounded theory, case study, phenomenology, narrative research) and guiding theory if appropriate; identifying the research paradigm (e.g., postpositivist, constructivist/ interpretivist) is also recommended; rationale

Researcher characteristics and reflexivity - Researchers' characteristics that may influence the research, including personal attributes, qualifications/experience, relationship with participants, assumptions, and/or presuppositions; potential or actual interaction between researchers' characteristics and the research questions, approach, methods, results, and/or transferability

Context - Setting/site and salient contextual factors; rationale

Sampling strategy - How and why research participants, documents, or events were selected; criteria for deciding when no further sampling was necessary (e.g., sampling saturation); rationale

Ethical issues pertaining to human subjects - Documentation of approval by an appropriate ethics review board and participant consent, or explanation for lack thereof; other confidentiality and data security issues

Data collection methods - Types of data collected; details of data collection procedures including (as appropriate) start and stop dates of data collection and analysis, iterative process, triangulation of sources/methods, and modification of procedures in response to evolving study findings; rationale

Data collection instruments and technologies - Description of instruments (e.g., interview guides, questionnaires) and devices (e.g., audio recorders) used for data collection; if/how the instrument(s) changed over the course of the study

Units of study - Number and relevant characteristics of participants, documents, or events included in the study; level of participation (could be reported in results) 


\begin{tabular}{|c|c|}
\hline & $\begin{array}{l}\text { Page/line } \\
\text { no(s). }\end{array}$ \\
\hline $\begin{array}{l}\text { Data processing - Methods for processing data prior to and during analysis, including } \\
\text { transcription, data entry, data management and security, verification of data integrity, } \\
\text { data coding, and anonymization/de-identification of excerpts }\end{array}$ & $\begin{array}{l}7-8 / 135- \\
146\end{array}$ \\
\hline $\begin{array}{l}\text { Data analysis - Process by which inferences, themes, etc., were identified and developed, } \\
\text { including the researchers involved in data analysis; usually references a specific } \\
\text { paradigm or approach; rationale }\end{array}$ & $\begin{array}{l}7-8 / 135- \\
146\end{array}$ \\
\hline $\begin{array}{l}\text { Techniques to enhance trustworthiness - Techniques to enhance trustworthiness and } \\
\text { credibility of data analysis (e.g., member checking, audit trail, triangulation); rationale }\end{array}$ & $\begin{array}{l}7-8 / 138- \\
146\end{array}$ \\
\hline \multicolumn{2}{|l|}{ Results/findings } \\
\hline $\begin{array}{l}\text { Synthesis and interpretation - Main findings (e.g., interpretations, inferences, and } \\
\text { themes); might include development of a theory or model, or integration with prior } \\
\text { research or theory }\end{array}$ & $\begin{array}{l}8 / 147- \\
151\end{array}$ \\
\hline $\begin{array}{l}\text { Links to empirical data - Evidence (e.g., quotes, field notes, text excerpts, photographs) to } \\
\text { substantiate analytic findings }\end{array}$ & $\begin{array}{l}8-12 / \\
152-288\end{array}$ \\
\hline \multicolumn{2}{|l|}{ Discussion } \\
\hline $\begin{array}{l}\text { Integration with prior work, implications, transferability, and contribution(s) to the field - } \\
\text { Short summary of main findings; explanation of how findings and conclusions connect } \\
\text { to, support, elaborate on, or challenge conclusions of earlier scholarship; discussion of } \\
\text { scope of application/generalizability; identification of unique contribution(s) to } \\
\text { scholarship in a discipline or field }\end{array}$ & $\begin{array}{l}13-16 / \\
289-361\end{array}$ \\
\hline Limitations - Trustworthiness and limitations of findings & $\begin{array}{l}15-16 / \\
353-361\end{array}$ \\
\hline \multicolumn{2}{|l|}{ Other } \\
\hline $\begin{array}{l}\text { Conflicts of interest-Potential sources of influence or perceived influence on study } \\
\text { conduct and conclusions; how these were managed }\end{array}$ & $\begin{array}{l}23 / 469- \\
470\end{array}$ \\
\hline $\begin{array}{l}\text { Funding - Sources of funding and other support; role of funders in data collection, } \\
\text { interpretation, and reporting }\end{array}$ & $\begin{array}{l}23 / 454- \\
457\end{array}$ \\
\hline
\end{tabular}

Source: O'Brien BC, Harris IB, Beckman TJ, Reed DA, Cook DA. Standards for reporting qualitative research: a synthesis of recommendations. Acad Med, 2014; 89(9):1245-51.

Additional file 4. Coding structure (23 codes developed based on evaluation questions) 
Construct Codes

Implementation

Program Role: How programs (i.e., funded health departments) interact with clinic sites and/or non-health system partners, and how programs support integrated implementation in clinics.

Partner Role: How non-health system partners interact with programs and/or clinic sites, length of relationship with the program, and how the partner organization supports the program's efforts to encourage integration in clinics.

Program Integration Description: How programs are integrating CRCCP with other cancer or chronic disease area programs within the health department.

Clinic Integration Description: How clinic sites are integrating implementation of CRC EBls with breast, cervical, heart disease, diabetes, and/or other screenings within the clinic.

Integrated Implementation Challenges and Solutions: Challenges related to integrating cancer and chronic disease prevention programs at the health department and strategies for overcoming challenges.

Integrated Implementation Facilitators: Factors that facilitated integrating cancer and chronic disease programs at the health department. of EBls.

Integrated Implementation Benefits: Benefits of integrating implementation

Lessons Learned/Recommendations for Programs: Lessons learned or recommendations for other health departments that want to move toward or sustain integration of cancer and other chronic disease programs.

Lessons Learned/Recommendations for Clinics: Lessons learned or recommendations for clinics that want to move toward integrated implementation of EBls to promote cancer and other chronic disease screenings.

Governance structure
Program Staffing and Infrastructure: Discussion of health department staffing structure and how it supports integrated implementation of CRCCP activities with those of other cancer or chronic disease prevention programs.

Clinic Staffing and Infrastructure: Clinic staffing structure and how it supports integrated implementation of EBls to promote cancer and chronic disease screenings.

Leadership support

Program Leadership Support: How health department leadership supports integration of CRCCP with other cancer or chronic disease prevention programs.

Clinic Leadership Support: How clinic leadership supports integrated implementation of EBls to promote cancer and other chronic disease screenings.

Funding environment
Coordination of Funding Streams: How the health department coordinates funding from various sources to support integrated implementation of EBIs in clinics.

Internal/External Incentives for Integrated Implementation: Any incentives that the health department provides to clinics to encourage integrated implementation. How external policies and incentives (e.g., National Quality Incentive Programs) affect integrated implementation and/or improvement of integrated implementation of EBls in clinics. 


\begin{tabular}{|c|c|}
\hline Construct & Codes \\
\hline \multirow[t]{3}{*}{$\begin{array}{l}\text { Information } \\
\text { sharing }\end{array}$} & $\begin{array}{l}\text { Program Information Sharing: How health department staff share } \\
\text { information between CRCCP and other cancer/chronic disease prevention } \\
\text { programs. }\end{array}$ \\
\hline & $\begin{array}{l}\text { Clinic Information Sharing: How staff within clinics/health systems share } \\
\text { information. }\end{array}$ \\
\hline & $\begin{array}{l}\text { Clinic Reporting: Any reporting challenges and/or benefits that are a result of } \\
\text { integrating implementation of EBls in clinics. }\end{array}$ \\
\hline \multirow[t]{5}{*}{ Sustainability } & $\begin{array}{l}\text { Sustainability Plans: Clinic systems, infrastructure, and/or } \\
\text { policies/procedures that are in place to sustain integrated implementation of EBIs. }\end{array}$ \\
\hline & $\begin{array}{l}\text { Sustainability Challenges: Challenges related to sustaining integration of } \\
\text { cancer and chronic disease prevention programs at the health department. }\end{array}$ \\
\hline & $\begin{array}{l}\text { Clinic Champions: The role of champions in supporting integrated } \\
\text { implementation of EBIs in clinics. }\end{array}$ \\
\hline & $\begin{array}{l}\text { Role of Funding: Resources available to sustain integrated implementation } \\
\text { of EBIs in clinics without CDC funding. }\end{array}$ \\
\hline & $\begin{array}{l}\text { Program Improvement: Systems, efforts, or processes that support } \\
\text { improvement of integrated implementation of EBls in clinics. }\end{array}$ \\
\hline
\end{tabular}

Note: CDC, Centers for Disease Control and Prevention; CRC, colorectal cancer; CRCCP, Colorectal Cancer Control Program; EBIs, evidence-based interventions.

Additional file 5. Brief description of clinic partner integrated implementation approaches, by site 


\begin{tabular}{|ll|}
\hline Site & Approaches to integrated implementation by program clinic partners \\
\hline $\begin{array}{l}\text { Rhode } \\
\text { Island }\end{array}$ & $\begin{array}{l}\text { Used a chronic care delivery model that integrates CRC screening with other cancer } \\
\text { and chronic disease screenings. Integration of CRC with other chronic disease } \\
\text { screenings is reflected in workforce development, clinical practice guidelines, EHR } \\
\text { prompts with physician reminders, and patient navigation. }\end{array}$ \\
\hline Nebraska & $\begin{array}{l}\text { Integrated CRC screening within an EHR-based provider reminders system (clinical } \\
\text { decision support rules) used for multiple screenings. }\end{array}$ \\
& $\begin{array}{l}\text { Used a FluFIT program to integrate CRC screening (FOBT kits or colonoscopy referral) } \\
\text { with flu shots. }\end{array}$ \\
\hline Washington & $\begin{array}{l}\text { Integrated CRC screening within EHR-based patient and provider reminders that are } \\
\text { used for multiple screenings. }\end{array}$ \\
& $\begin{array}{l}\text { Expanded interventions focused on reducing structural barriers (e.g., providing mobile } \\
\text { mammography and transportation vouchers) to include barriers for CRC screening } \\
\text { (e.g., mailing FIT kits to patients due for CRC screening). }\end{array}$ \\
Kentucky & $\begin{array}{l}\text { Integrated CRC screening into an existing patient reminder system (i.e., phone calls to } \\
\text { remind patients about need for CRC screening, other cancer screenings). } \\
\text { Reduced structural barriers for CRC screening by including screening as part of "max } \\
\text { packing" appointments that also included flu shots and/or mammograms. }\end{array}$ \\
\hline
\end{tabular}

Note: CRC, colorectal cancer; EHR, electronic health record; FIT, fecal immunochemical test; FOBT, fecal occult blood test.

\section{Figures}


- Integrate public health and primary care

- Use evidence-based strategies to maximize limited public health dollars

- Establish partnerships to support implementation

- Implement sustainable health system changes

- Focus on defined, high-need populations

- Encourage innovations in adaptations of evidence-based interventions

- Use data for program improvement, performance management, and reporting

\section{Figure 1}

Tenets of the Colorectal Cancer Control Program
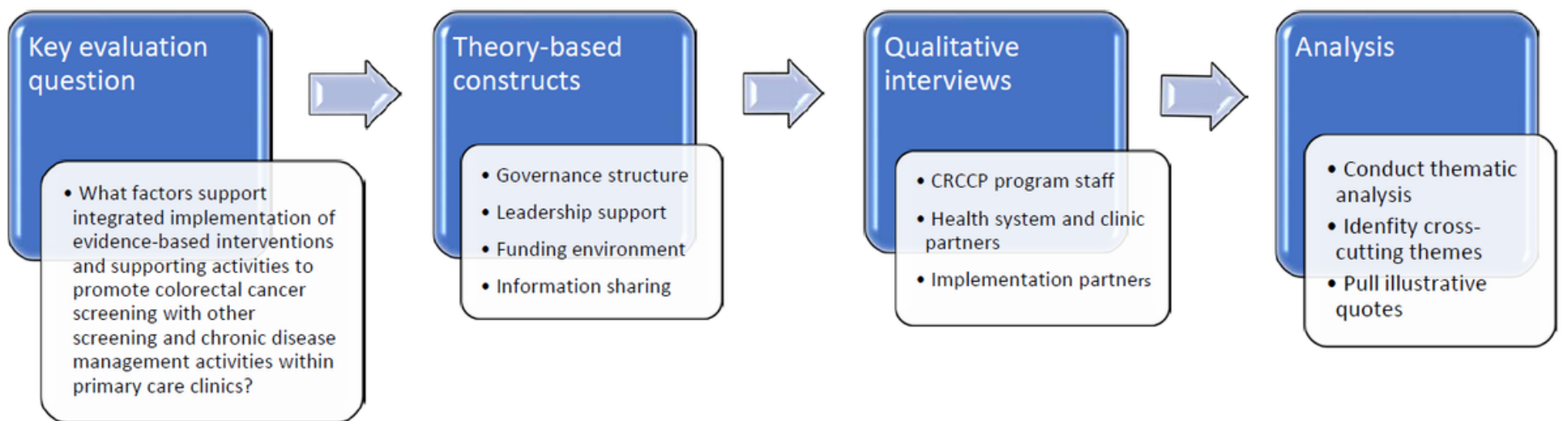

\section{Figure 2}

Methodological Approach 


\section{PUBLIC HEALTH PROGRAM SUPPORT}

1 FUNDING ENVRONMENT

- Programs coordinate funding streams from multiple

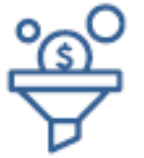
programs, and consolidate health systems and primary care clinics' funding applications

- Programs fund partners to provide support to health systems and primary care clinics

\section{Health System \& Primary Care Clinic Characteristics}

2 GOVERNANCE STRUCTURE

Effective teams that supports collective responsibility for patient and delivery of integrated care
3 INFORMATION SHARING

Effective use of EHR systems to share patient data and support integrated implementation

\section{LEADERSHIP} SUPPORT

Strong and ongoing support from clinic leaders who promote integrated implementation
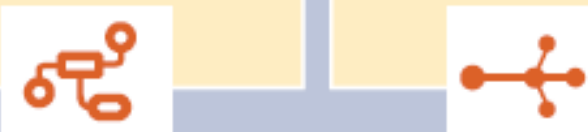

\section{INTENDED OUTCOMES}

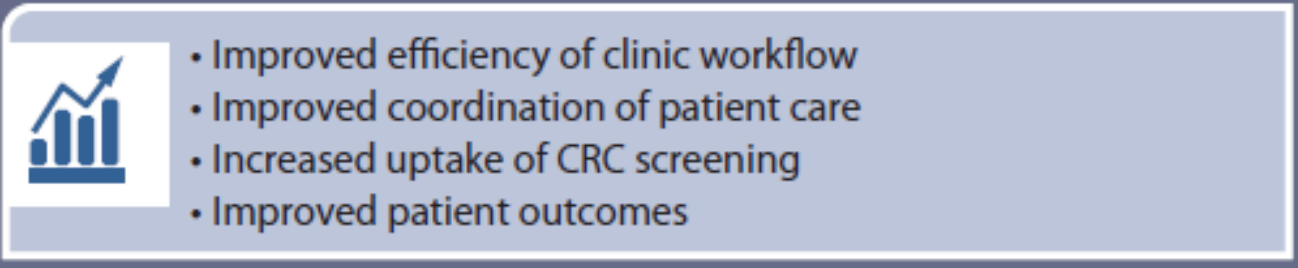

\section{Figure 3}

Program and clinic partner factors supporting integrated implementation 